\title{
Hedging our bets
}

\author{
Chadrick E. Denlinger, MD
}

\author{
From the Department of Surgery, Medical University of South Carolina, Charleston, SC. \\ Disclosures: Author has nothing to disclose with regard to commercial support. \\ Received for publication Dec 28, 2017; accepted for publication Jan 10, 2018; available ahead of print Feb 2, \\ 2018. \\ Address for reprints: Chadrick E. Denlinger, MD, Medical University of South Carolina, 25 Courtenay Dr, Suite \\ 7018, MCS 2 95, Charleston, SC 29425 (E-mail: denlinge@musc.edu). \\ J Thorac Cardiovasc Surg 2018;155:2177-8 \\ 0022-5223/\$36.00 \\ Copyright (C) 2018 by The American Association for Thoracic Surgery \\ https://doi.org/10.1016/j.jtcvs.2018.01.012
}

A time-honored principle of financial investment is portfolio diversity, with allocation of resources into widely disparate assets. An analogous approach applies to lung cancer treatment. The past decade has witnessed an explosion of treatment options available to patients with advanced non-small cell lung cancer. The first targeted protein pushing the envelope beyond traditional cytotoxic agents was the epithelial growth factor receptor, and this was followed closely by a significant number of additional growth factor receptors. Although each targetable growth factor receptor may be treated in small, discrete populations, depending on specific mutations, an Achilles heel of all these receptors is the common intracellular second messenger K-Ras, which remains untreatable. K-Ras mutations thus circumvent the utility of any growth factor receptor targeting agent. Even in the absence of K-Ras mutations, a limitation of growth factor targeting agents is the emergence of resistance, which develops through augmentation of redundant growth factor pathways or the acquisition of additional mutations within the targeted growth factor and obviates the previous favorable drug response.

The advent of checkpoint inhibitors that target the programmed death receptor (PD-1) or programed death receptor ligand (PD-L1) activate cytotoxic T-cells to combat malignancies, including lung cancer. These immunotherapies have opened an entirely new treatment avenue that is independent of traditional cytotoxic therapy and growth factor targeting agents. Importantly, K-Ras mutations that circumvent any growth factor targeting agent have no impact on the efficacy of immunotherapy such as checkpoint inhibitors. In a similar way, Ella and colleagues ${ }^{1}$ are to be congratulated for exploring, in their article in this issue of the Journal, yet another completely independent avenue of cancer treatment. Although the concept of the concept of targeting matrix metalloproteinases (MMPs) remains in the preclinical arena, the potential for clinical exploitation is entirely plausible.

Ella and colleagues ${ }^{1}$ demonstrated that lung cancers frequently overexpressed MMP-12 and that greater MMP-12 expression was correlated with decreased long-

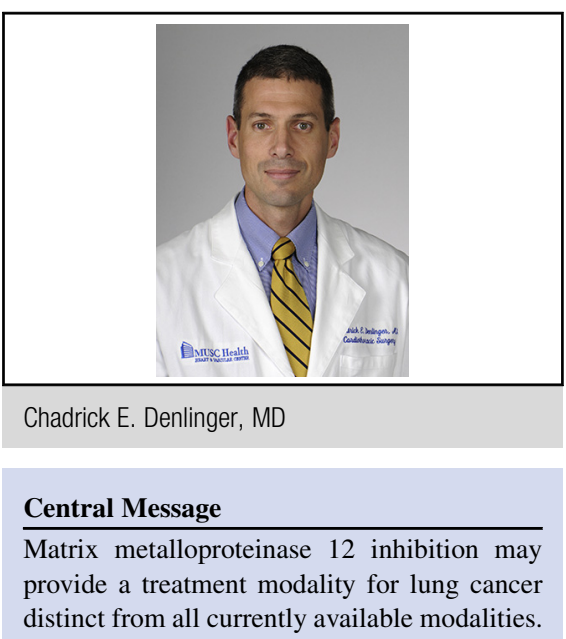

See Article page 2164.

term survival. They also demonstrated that MMP-12 expression was markedly upregulated in tumor cells that were orthotopically injected into mouse lungs and that MMP-12 knockout cells formed smaller tumors than did similar cells with normal MMP-12 expression. MMP-12 has previously been linked to tumor cell invasion and metastasis in lung cancer, as well as in such other solid cancers as esophageal cancer, melanoma, and breast cancer. ${ }^{2-4}$ There thus is a growing body of evidence supporting a functional role for MMP-12 in tumor invasion and metastasis in patients with lung cancer. In other studies, small-molecule inhibition of MMP-12 was shown to have a therapeutic effect on anastomotic strength after colon resection in rodents. ${ }^{5}$

The exploration of MMP-12 inhibition as a means of improving the outcomes of patients with lung cancer opens a novel paradigm, with no foreseeable overlap with currently available treatment modalities. Inhibition of a tumor cell's ability to interact with the intracellular matrix holds the potential for contributing additive or synergistic treatment responses. At minimum, targeting the intracellular matrix interactions can provide a hedge for when cancers acquire additional mutations and exhibit growth after a previous favorable response to a targeted therapy.

\section{References}

1. Ella E, Harel Y, Abraham M, Wald H, Benny O, Karsch-Bluman A, et al. Matrix metalloproteinase 12 promotes tumor propagation in the lung. $J$ Thorac Cardiovasc Surg. 2018;155:2164-75.e1. 
2. Han F, Zhang S, Zhang L, Hao Q. The overexpression and predictive significance of MMP-12 in esophageal squamous cell carcinoma. Pathol Res Pract. 2017;213: 1519-22.

3. Zhang Z, Zhu S, Yang Y, Ma X, Guo S. Matrix metalloproteinase-12 expression is increased in cutaneous melanoma and associated with tumor aggressiveness. Tumour Biol. 2015;36:8593-600.
4. Hughes S, Agbaje O, Bowen RL, Holliday DL, Shaw JA, Duffy S, et al. Matrix metalloproteinase single-nucleotide polymorphisms and haplotypes predict breast cancer progression. Clin Cancer Res. 2007;13:6673-80.

5. Krarup PM, Eld M, Jorgensen LN, Hansen MB, Ågren MS. Selective matrix metalloproteinase inhibition increases breaking strength and reduces anastomotic leakage in experimentally obstructed colon. Int J Colorectal Dis. 2017;32:1277-84. 